\title{
The brain basis of syntactic processes: functional imaging and lesion studies
}

\author{
Angela D. Friederici* and Sonja A. Kotz \\ Max Planck Institute of Cognitive Neuroscience, P.O. Box 500 355, 04303 Leipzig, Germany
}

\begin{abstract}
Language comprehension can be subdivided into three processing steps: initial structure building, semantic integration, and late syntactic integration. The two syntactic processing phases are correlated with two distinct components in the event-related brain potential, namely an early left anterior negativity (ELAN) and a late centroparietal positivity (P600). Moreover, ERP findings from healthy adults suggest that early structure-building processes as reflected by the ELAN are independent of semantic processes. fMRI results have revealed that semantic and syntactic processes are supported by separable temporofrontal networks, with the syntactic processes involving the left superior temporal gyrus (STG), the left frontal operculum, and the basal ganglia (BG) in particular. MEG data from healthy adults have indicated that the left anterior temporal region and the left inferior frontal region subserve the early structure building processes. ERP data from patients with lesions in the left anterior temporal region and from patients with lesions in the left inferior frontal gyrus support this view, as these patients do not demonstrate an ELAN, although they do demonstrate a P600. Further results from patients with BG dysfunction suggest that parts of this subcortical structure are involved in late syntactic integrational processes. The data from the different experiments lead to the notion of separable brain systems responsible for early and late syntactic processes, with the former being subserved by the inferior frontal gyrus and the anterior STG and the latter being supported by the BG and more posterior portions of the STG.
\end{abstract}

(C) 2003 Elsevier Inc. All rights reserved.

\section{Introduction}

Lesion studies that correlate particular behavioral patterns with the localization of brain lesions have provided crucial information about the brain-cognition relationship for more than a century. With the advent of functional brain imaging techniques toward the end of the past century new possibilities to describe this relationship have arisen.

Here we will focus on a specifically human cognitive ability, namely language, and concentrate on the processing of syntactic information, which is one of its core functions. Although the ultimate goal of language understanding is to extract the meaning of a given utterance, the syntactic processing capacity is a necessary precondition for normal sentence comprehension. It is the syntactic information that marks the grammatical relation between the elements in a sentence, thereby signaling "who is doing what to whom." For example, a sentence like The cat that the dog hunted is

* Corresponding author. Fax: +49-0-3-41-99-40-113.

E-mail address: angelafr@cns.mpg.de (A.D. Friederici). black can be understood only when processing the function word "that" correctly (see Caplan, 1995, 2001).

Models of language comprehension agree on the notion that syntactic and semantic information has to be integrated within a minimum of time in order to guarantee fast understanding. They differ in their views on the time course of these processes. Interactive models assume that the parser uses the different information types immediately, i.e., when available in an interactive manner (Bates and MacWhinney, 1987; MacDonald et al., 1994; Marslen-Wilson and Tyler, 1980; Taraban and McClelland, 1988). Modular, syntaxfirst theories claim that the parser incrementally constructs a syntactic structure on the basis of word category information independent of semantic information and that thematic role assignment takes place only during a second stage (Fodor, 1983; Frazier and Fodor, 1978). Behavioral studies have provided evidence for both views.

Recently, a number of studies have investigated the brain basis of language comprehension by means of functional magnetic resonance imaging (fMRI) or event-related brain potentials (ERPs) using different presentation modes, stimulus 
materials, and experimental tasks (for reviews see Friederici, 2002; Hickok and Poeppel, 2000). The present article will report studies that used the same type of stimulus material, applying different techniques such as fMRI, ERP, and magnetoencephalography (MEG) to healthy subjects and different patient groups. The combined findings allow the formulation of a brain-based model of language comprehension.

\section{Materials used in the different studies}

The stimulus material in all studies consisted of sentences that were correct, semantically incorrect, and/or syntactically incorrect. Syntactically incorrect sentences contained a phrase structure violation as in (1), below, in which the preposition im needs to be followed by a noun rather than a verb to formulate a correct German sentence. Semantically incorrect sentences were presented as selectional restriction violations as in (2). Moreover, in some studies sentences in which the target was semantically and syntactically incorrect, as in (3), were used. Brain responses to these incorrect sentences were compared with those to correct sentences ((4), for a detailed description of material see Hahne and Friederici, 2002).

(1) Syn incorr: Das Eis wurde im cream was in the eaten.

(2) Sem incorr: Der Vulkan wurde gegessen./The volcano was eaten.

(3) Syn/sem incorr: Das Türschloss wurde im gessen./The door lock was in the _eaten.

(4) Corr: Das Eis wurde gegessen./The ice cream was eaten.

In all experiments sentences of these types were presented auditorily as connected speech. Participants in the different experiments were required to perform a delayed grammaticality judgment task after each sentence.

Information about the methodological details of brain activity registration and the analysis procedures is given in the respective publications of the studies summarized below.

\section{Neurotopography of syntactic and semantic processes: $f$ MRI study}

In an event-related fMRI experiment with healthy young adults we tried to identify the neural network supporting semantic and syntactic processes by comparing the brain's activation of syntactically (1) and semantically (2) incorrect sentences compared to correct (4) sentences (Friederici et al., 2003b). The results revealed two separate temporofrontal networks for semantic and syntactic processes (see Fig. 1). Semantic processes involved the middle and posterior portion of the superior temporal gyrus (STG) and the insular cortex bilaterally. Syntactic processes, operationalized as local phrase structure building, engaged the anterior portion of the left STG and the deep frontal operculum. Additional activation was observed in the left basal ganglia (BG), in particular the putamen, and the left posterior portion of the STG. This finding is in agreement with studies in other languages, which reported a functional specification of the pars opercularis subserving syntactic processes in addition to temporal activations (e.g., Embick et al., 2000; Newman et al., 2003). Studies using explicit tasks focusing on either syntactic or semantic processing have provided evidence for a functional separation of BA 44 and BA 45 in the left inferior frontal gyrus (IFG) with BA 45 supporting semantic aspects and BA 44 subserving syntactic aspects of processing (e.g., Friederici et al., 2000b).

\section{Temporal structure of syntactic and semantic processes: ERP studies}

Language processing unfolds in time millisecond by millisecond. We therefore conducted a number of ERP experiments with healthy young adults, first, looking at syntactic and semantic processes separately and, second, at the temporal structure of the interplay between syntactic and semantic processes.

\section{Syntactic versus semantic processes}

In an auditory ERP experiment that presented syntactically incorrect sentences as in (1), semantically incorrect sentences as in (2), and correct sentences as in (4) auditorily the following ERP effects were found (Friederici et al., 1993; Hahne and Friederici, 2002): Similar to earlier studies reported in the literature an N400 component was elicited by the word that rendered a sentence semantically incorrect (Holcomb and Neville, 1991; Kutas and Hillyard, 1984 for review see Kutas and Federmeier, 2000; Kutas and Van Petten, 1994). Similar N400 effects, however, were also observed out of sentential context when two words standing in close semantic relation are processed (e.g., Van Petten, 1993). This suggests that the semantic relation between words is the crucial factor in determining the N400 rather than sentential integration.

For the syntactically incorrect condition two ERP components were found, an early left anterior negativity (ELAN) between 150 and $250 \mathrm{~ms}$ and a late bilateral centroparietal positivity around $600 \mathrm{~ms}$ (P600). Earlier studies on syntactic processing had shown similar ERP components. Most studies investigating outright syntactic violations observed a left anterior negativity preceding the late P600 component. Such a biphasic pattern was reported for phrase structure violations realized as word category errors (Friederici et al., 1996, 1993; Hahne and Friederici, 1999, 2002; Neville et al., 1991) and for agreement violations 
1

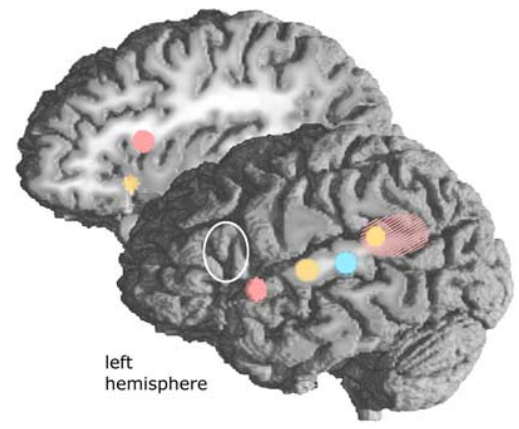

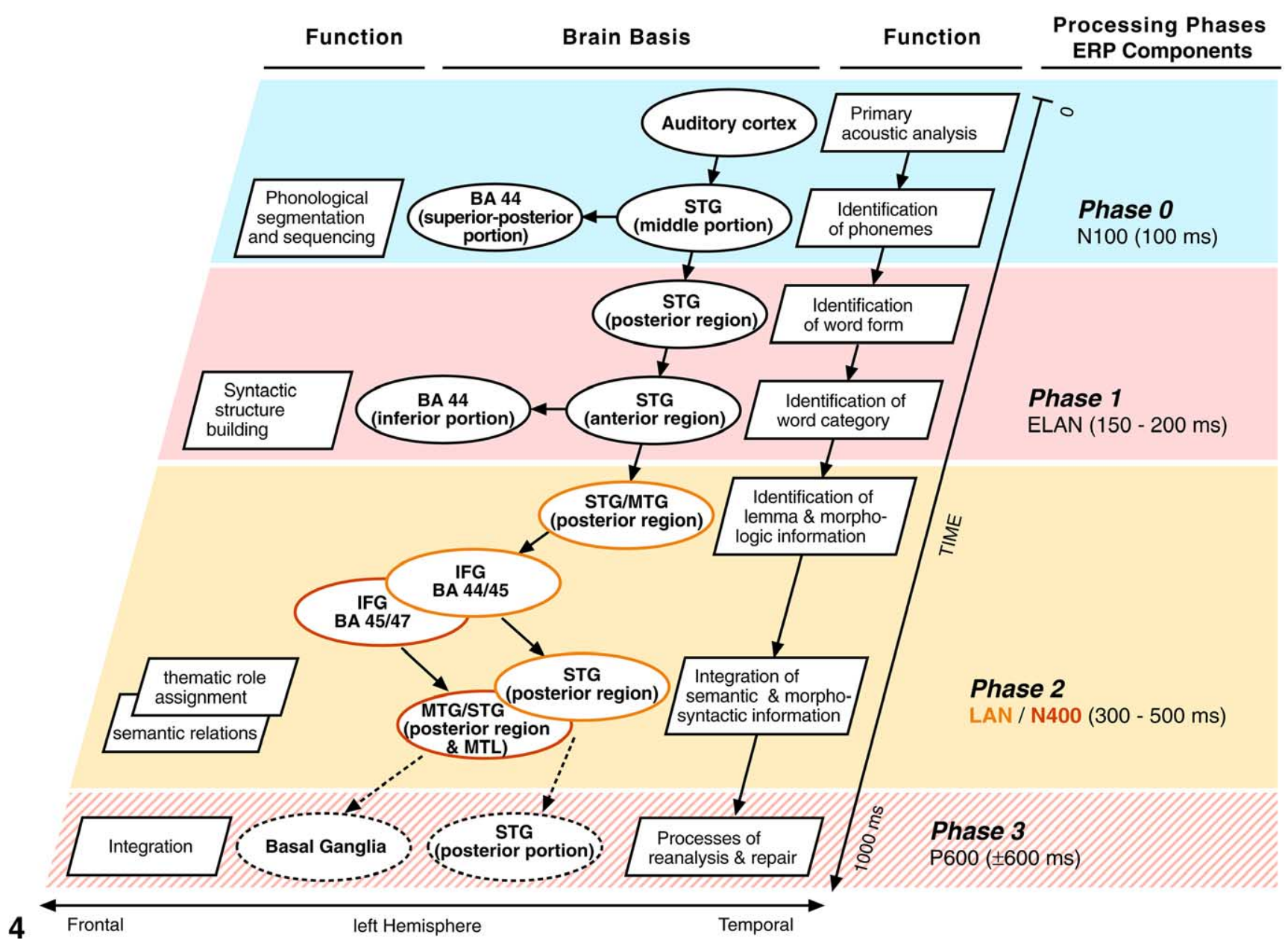

Fig. 1. Displayed are the syntax- and semantic-related brain regions. The blue circle marks the region supporting acoustic processes. The other colored circles and ellipses represent the maxima of the fMRI activation for syntactic in the IFG $(-41,-2,13)$ and the anterior STG $(-53,-1,0)$ indicated by red-filled circles, in addition, and in the posterior STG $(-61,-40,20)$ indicated by the red-striped ellipsis in the STG. This area is striped as it was found to be active during syntactic and semantic processes in a recent fMRI experiment (Friederici et al., 2003c). Activations indicated by the red-filled circles mark regions involved in early syntactic processes as patients with lesions in these regions do not demonstrate an ELAN, an ERP component correlated with early local structure building processes. The red-striped ellipsis marks a region assumed to be involved in late syntactic processes as patients with lesions in this region do not display a P600, an ERP component correlated with late syntactic integration processes. The open white circle marks the area known to support the processing of syntactically complex, noncanonical sentences (for a review see Friederici, 2002). Semantic processes are subserved by those regions indicated by orange circles in the IFG and the STG.

Fig. 4. Adapted version of the neurocognitive model of auditory language comprehension (Friederici, 2002). The model was based on a review of ERP, PET, and fMRI sentence processing studies. The present article discusses the brain basis of phase 1 (ELAN) and phase 3 (P600), as well as the temporal and functional relation of phase 1 (ELAN) and semantic processes (N400) as part of phase 2 in some detail. Due to space restrictions processes of thematic role assignment on the basis of morphosyntactic information are not discussed here. Color coding of the different phases is matched to the respective brain activations displayed in Fig. 1. 
(Deutsch and Bentin, 2001; Gunter et al., 1997, 2000; Penke et al., 1997). The latency of the left anterior negativity seems to vary as a function of the violation type, i.e., ELAN for phrase structure violations and LAN for agreement violations. Moreover, it appears to vary as a function of the violation point in the critical word. For example, a left anterior negativity for a phrase structure violation was observed around 150-200 ms post-word onset when the crucial word category information (verb vs noun) was located in the prefix (beginning of the word), e.g., the prefix ge- as a marker for a verb particle form in German, similar to the suffix -ed in English (Friederici et al., 1993; Hahne and Friederici, 1999, 2002). A left anterior negativity was found around 350-500 ms post-word onset when the crucial word category information (verb vs noun) was located in the suffix (end of the word), e.g., veredelt vs Veredelung in German, similar to refined vs refinement in English. Note that in this latter case the left anterior effect is early with respect to onset of the suffix, i.e., the word category identification point (Friederici et al., 1996). The P600 was observed with outright syntactic violations requiring syntactic repair (Hagoort et al., 1993; Friederici et al., 1993; Münte et al., 1993; Neville et al., 1991; Rösler et al., 1993 for a recent review see Friederici, 2002), as well as in correct but temporarily ambiguous sentences for the critical disambiguating element signaling the need for syntactic reanalysis (Osterhout and Holcomb, 1992, 1993; Osterhout et al., 1994; Mecklinger et al., 1995). The functional interpretation of the P600 varies from being the index of syntactic processes (Hagoort et al., 1993), of secondary syntactic processes such as reanalysis and repair (Friederici and Mecklinger, 1996), or of syntactic integration processes in general (Kaan et al., 2000).

In agreement with these earlier studies the three components observed in this experiment were taken to reflect different stages of processing during language comprehension: an initial stage of local structure building reflected by the ELAN as soon as word category information is available, a second stage of lexical-semantic processes reflected by the N400, ${ }^{1}$ and a third stage involving processes of syntactic revision and integration reflected by the P600 (see also Friederici, 1995, 2002).

Given the finding of the different ERP components/ subprocesses some questions arose: the first concerned the temporal and functional separation of the different subprocesses and the second concerned the neural basis of the syntactic subprocesses reflected in the ELAN and those reflected in the P600.

\footnotetext{
${ }^{1}$ Note that we will not discuss the $\mathrm{N} 400$ as a reflection of impossible thematic role assignment (Bornkessel, 2002; Frisch and Schlesewsky, 2001) in instances in which case-marking information allows a direct mapping onto thematic/semantic roles. For details see Bornkessel (2002).
}

The interplay of syntactic and semantic information

The first issue was investigated in two experiments in which the critical violating lexical element was both semantically and syntactically incorrect as in sentence type (3) (Das Türschloss wurde im__ gegessen./The door lock was in the __eaten. vs Das Eis wurde gegessen./The ice cream was eaten.) (Hahne and Friederici, 2002). In this experiment subjects listened to correct (4) and semantically (2) and syntactically (1) incorrect sentences (similar to those in the experiment reported above), but moreover to sentences which were both semantically and syntactically incorrect. As expected semantically incorrect sentences elicited an N400, syntactically incorrect sentences a biphasic ELANP600 pattern. The double violation also elicited a biphasic ELAN-P600 pattern, but no N400 (see Fig. 2). This finding provides strong support for the independence of the early syntactic processes from semantic information. Moreover, it demonstrates that early syntactic processes can influence the following semantic processes (no N400).

From this result the question arose whether the independence of early syntactic structure-building processes is due to the temporal ordering of when syntactic and semantic information becomes available during word recognition (i.e., syntactic information is available prior to semantic information) or whether the independence is functionally based (i.e., syntactic information is used prior to semantic information).

The German language is an ideal testing ground for this question as quite a number of multimorphemic-derived forms are marked either as a verb in the prefix or as a noun in the suffix (e.g., Veredelung/refinement vs veredelt/refined). Note, that the word stem veredel- has no independent word status such that in both verbs and nouns the word category information necessary to build the local syntactic structure is available at the suffix position. Thus, these latter forms allow one to construct sentences in which the target word is a semantically and syntactically incongruent continuation of the prior sentences, with semantic information encoded in the word stem, however, being available earlier than the word category information encoded in the suffix, i.e., at the end of the word (5). Sentences of this type were presented together with correct sentences (6).

(5) Syn/sem incorr: Das Buch wurde trotz verpflanzt von einem Verleger, den wenige empfahlen./The book was despite replanted by a publisher who(m) few recommended.

(6) Corr: Der Strauch wurde trotz Verpflanzung vernachlässigt von einem Gärtner, den wenige empfahlen./The bush was despite replanting neglected by a gardener who $(m)$ few recommended.

The data from an experiment in which these sentence types were presented auditorily together with single syntactic violations and single semantic violations, as in (1) and 


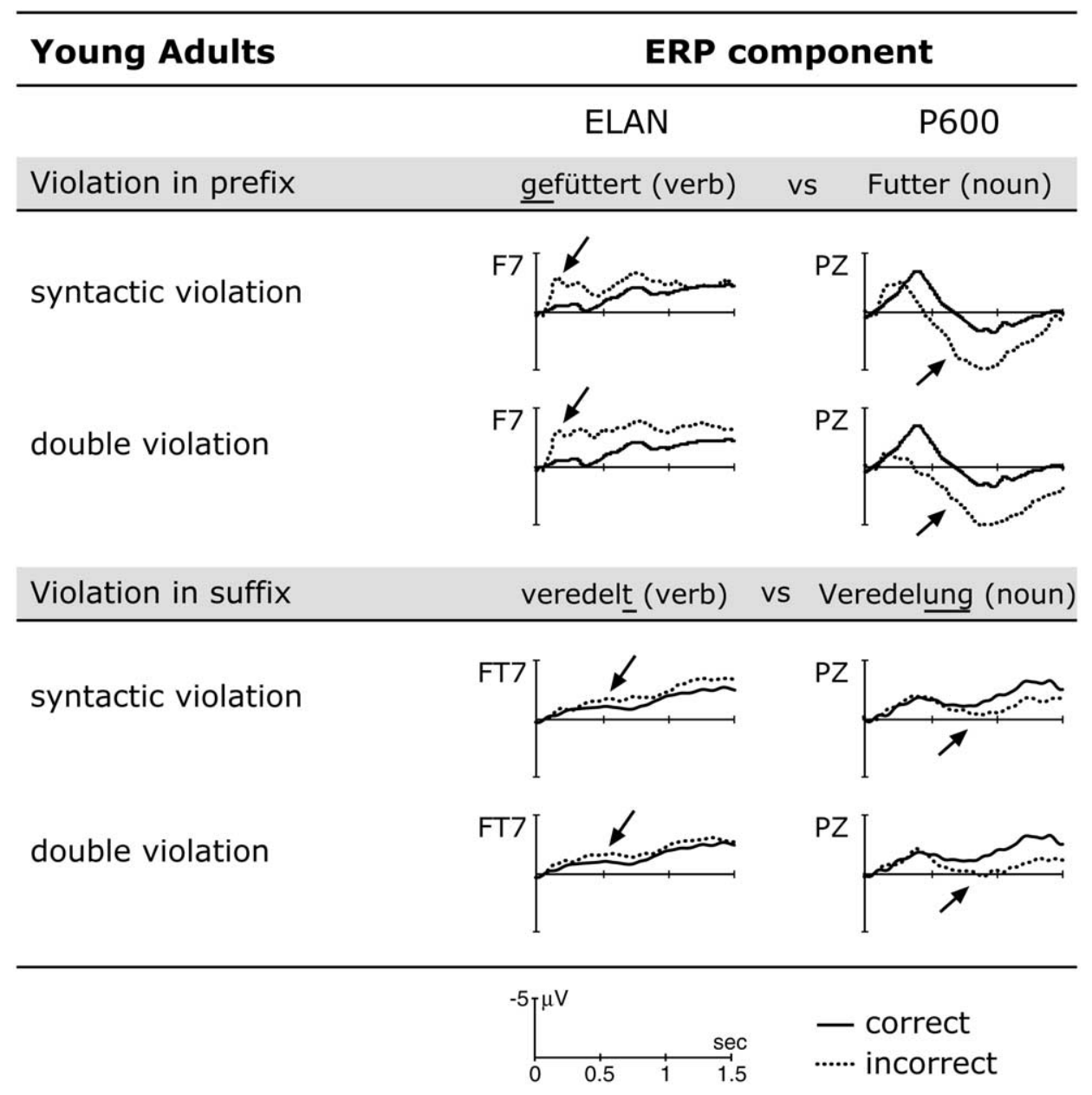

Fig. 2. Grand average ERPs for selected electrodes from left frontal region (F7, FT7) and centroparietal region (PZ) from experiments investigating sentences containing syntactic violations and so-called double violations, i.e., the target is syntactically and semantically incorrect. The vertical line at each electrode site marks the onset of the critical word in the correct condition and in the incorrect condition. The arrow at electrodes F7, FT7 indicates the ELAN effect and at electrodes PZ the P600 effect. Top: data from an experiment in which the critical word category information was encoded in the prefix (beginning of word) (Hahne and Friederici, 2002). Bottom: data from an experiment in which the critical word category information was encoded in the suffix of the word (end of word) (Friederici et al., 2003a).

(2), were straightforward (Friederici et al., 2003a). The double-violation condition elicited a left anterior negativity between 400 and $800 \mathrm{~ms}$ (i.e., about $100 \mathrm{~ms}$ after the word category decision point resembling an ELAN), no N400 effect, but a P600 which was larger for the double violation than for the single syntax violation condition (see Fig. 2). These findings are clear evidence for the functional independence of structure-building processes from semantic information as the ELAN is elicited even through the word category information (suffix) comes in after the semantic information (word stem). The observation that the P600 varies as a function of both syntactic and semantic information suggests that both information types may interact during the late integration phase. A similar result for the P600 was reported by Gunter et al. $(1997,2000)$ when morphosyntactic and semantic anomalies were crossed in reading studies. These results suggest that the assumed late phase reflects sentential integration rather than purely syntactic processes.

The presence of the ELAN and the absence of an N400 effect in our study point toward a functional priority of local phrase-structure-building processes as expected on the basis of syntax-first models. Such a pattern, however, is not expected if the word stem itself represents an independent lexical entry carrying word category information (e.g., invest-ment, first part is a verb). Under such a condition the incrementally working parser would, once word category information of the stem (invest-verb) is available, try to integrate this part into the preceding context and detect a syntactic word category mismatch only later (e.g., The brother knows how to invest-ment the money). A double violation (e.g., The dog knows how to invest-ment the money) consequently would result in an N400 
at the stem (invest), as this causes a semantic expectancy mismatch, and a following ELAN at the suffix (-ment), as this brings up the syntactic word category mismatch. We think that the observed presence of the ELAN independent of prior semantic information in all experiments investigating double violations is very strong support for the view that structure building is independent of semantic aspects as hypothesized by syntax-first models.

\section{Neural basis of the two syntactic subcomponents: dipole modeling and patient studies}

The second major issue investigated concerned the specification of the brain areas supporting the early syntactic structure-building processes and the late syntactic integration processes. In principle there are two possibilities to identify the brain basis of the early versus the late syntactic processes. First, current source density mapping (Knoesche et al., 1999) and dipole modeling (Friederici et al., 2000b) of data from MEG experiments with a large number of electrode channels may provide relevant information about the brain regions involved. Second, ERP studies with patients suffering from localized brain lesions can inform us about which brain tissue supports which syntactic process. Given today's tools of dipole analysis, MEG, however, can be applied with sufficient local precision only for early components such as the ELAN.

\section{Dipole modeling of MEG data from healthy young adults}

An MEG experiment using the same stimulus material as in earlier experiments was conducted focusing on the early syntactic process. Dipole modeling for the early time window covering the ELAN component was conducted using the fMRI data as a constraint. Based on an fMRI study in which correct sentences similar to those in (4) and syntactically incorrect sentences similar to those in (1) were presented auditorily (Meyer et al., 2000) two locations were selected for each hemisphere as the seed points for constrained dipole fitting. Seed points in the left hemisphere were in the IFG $(-41,10,13)$ and in the STG $(-50,-8,1)$ and in the right hemisphere in the IFG $(48,11,10)$ and in the STG $(55,-8,5)$ according to Talairach and Tournoux (1988). Dipole modeling of the magnetic ELAN effect revealed two dipoles in each hemisphere, but with stronger dipoles in the left hemisphere. For each subject one dipole was located in the anterior portion of the superior temporal region and one in the inferior frontal region (Friederici et al., 2000a). This result suggests that the hemodynamic activation observed in the anterior portion of the STG and in the frontal operculum during syntactic processing in the fMRI experiment (Friederici et al., 2003c) subserves early structure-building processes. It furthermore raises the possibility that the additional activation in the putamen of the
BG and the posterior portion of the STG is correlated with late syntactic processes not captured by the early time window.

\section{ERP studies with different patient groups}

The brain basis of the early and the late syntactic processes was further investigated in ERP experiments using different patient groups. By presenting the same sentence material as in the previous experiments the following patient groups were tested: (a) patients with lesions in the left frontal region (Friederici et al., 1998, 1999), (b) patients with lesions in the left BG (Friederici et al., 1999; Frisch et al., 2003; Kotz et al., 2003a, b), (c) patients with lesions in the left anterior temporal lobe (Kotz et al., 2003c), (d) patients with lesions in the right anterior temporal lobe and the right BG (Kotz et al., 2003c), and (e) patients with Parkinson's disease suffering from a degeneration of BG (Friederici et al., 2003b).

The ERP findings from the different patient studies are straightforward. The ELAN component was absent in patients with lesions in the left frontal cortex and with lesions in the anterior temporal lobe, revealing that these structures are relevant for processes of initial syntactic building. Fig. 3 summarizes the presence or absence of the syntax-related ERP components for patients with lesions in different brain regions. In contrast, the ELAN component was observed in patients with lesions in the left BG, in patients with lesions in the right anterior temporal lobe and the right $\mathrm{BG}$, and in Parkinson's patients, indicating that these structures are not primarily involved in processes of early structure building. The results from the left-hemisphere-damaged patients are compatible with the findings from the fMRI and the MEG study demonstrating a crucial involvement of the left anterior STG and the left frontal operculum in early syntactic structure building.

With respect to the time window covering the P600 the following pattern in the different patient groups was found. Patients with lesions in the left frontal cortex and the left anterior temporal lobe, characterized by the absence of the ELAN, displayed a clear P600 effect. Patients with lesions in the left BG showed no P600 effect, and patients with lesions in the right anterior temporal lobe and the right $\mathrm{BG}$ demonstrated a reduced left-lateralized P600 effect. This latter finding suggests that the BG modulate syntactic processes as reflected by the P600 (for an elaboration of this claim see Kotz et al., 2003b).

When relating these findings to the fMRI activations found in the study using the same stimulus material (Friederici et al., 2003c) one additional brain area must be considered, namely the posterior portion of the STG. This area showed an increased hemodynamic response in both the syntactic and the semantic violation condition compared to the correct condition (Friederici et al., 2003b). A similar result was reported in another recent fMRI study including 


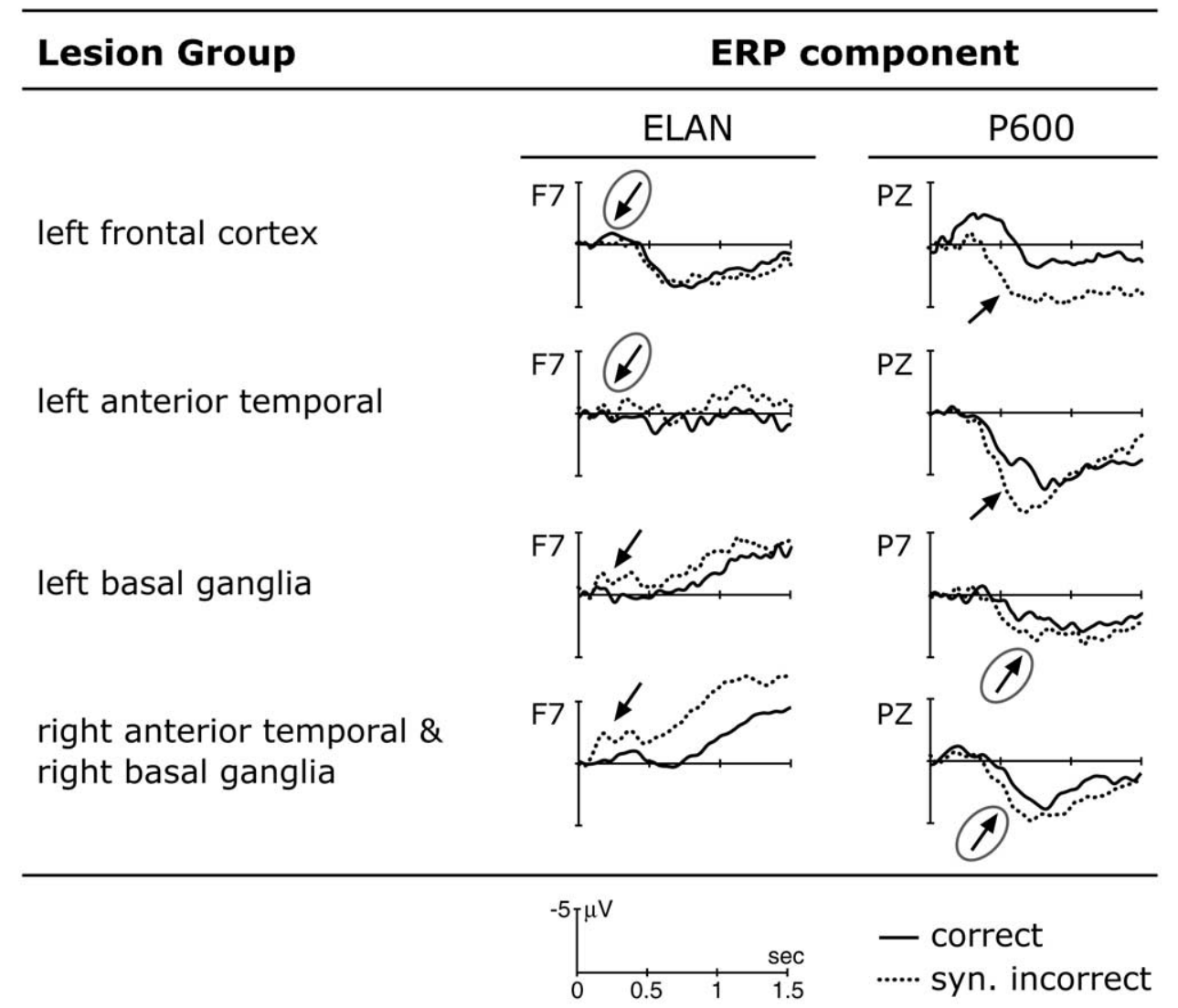

Fig. 3. Grand average ERPs for selected electrodes from left frontal region (F7) and centroparietal region (PZ, P7) of different patient groups: patients with lesions in the left frontal cortex (Friederici et al., 1999), patients with left anterior temporal lesions (Kotz et al., 2003c), patients with left basal ganglia lesions (Friederici et al., 1999), patients with lesions in the right anterior temporal region and the right basal ganglia (Kotz et al., 2003c). The vertical line at each electrode site marks the onset of the critical word in the correct condition and in the incorrect condition. Arrows mark the presence of the ELAN or P600 effect. Circled arrows mark the absence or reduction of these effects. Electrode P7 was chosen for the left basal ganglia group to demonstrate the selective reduction of the P600 over the left parietal region.

both a syntactic and a semantic/thematic violation condition (Newman et al., 2003). Friederici et al. (2003c) proposed a subdivision of the STG into functionally separable portions, namely the anterior portion of the STG supporting local structure-building processes, its middle portion subserving semantic processes, and its posterior portion being involved in processes of final sentential integration. In this view the posterior portion of the STG, in addition to the left BG, may possibly contribute to the late integration processes underlying the P600. Although the P600 is mainly elicited by syntactic anomalies (Osterhout and Holcomb, 1992; Hagoort et al., 1993), the present interpretation of the processes underlying the P600 is supported by the finding that the P600 has been observed to vary as a function of difficulties of syntactic integration (Kaan et al., 2000) and, moreover, as a function of difficulties of semantic integration in syntactically incorrect sentences (Gunter et al., 2000). Further studies will have to show whether the proposed functional subdivision of the STG during sentence comprehension holds.

\section{Conclusion}

On the basis of the results of fMRI, ERP, MEG, and patient studies reported here and those in the literature (for recent reviews see Friederici, 2002; Kaan and Swaab, 2002; Kotz and Friederici, 2003) we propose the following brainbased model of language comprehension.

There are separate temporofrontal circuits for the processing of syntactic and semantic information in the left hemisphere. The findings presented here and reported in the literature suggest that the temporal region supporting syntactic processes involves the anterior STG, in addition to the posterior STG, and the frontal region the posterior ventral portion of the IFG (BA 44), the frontal operculum, and the BG. The temporal region supporting lexical-semantic processes appears to involve the middle portion and the posterior portion of the middle temporal gyrus and the STG; its frontal part consists of the anterior ventral portion of the IFG (BA 45) (compare Fig. 4).

This functional separation in the IFG may be corre- 
lated with the cytoarchitectonic differences reported by Amunts et al. (1997) in adults. Interestingly, there appears to be a codevelopment of structure and function. Amunts et al. (2003) reported that an adult-like cytoarchitectonic asymmetry toward the left hemisphere differs in its developmental time course. While such an asymmetry is present for BA 45 by the age of 5 years, it is present for BA 44 only by the age of 11 years. This result corresponds to the behavioral finding that adult-like syntactic processes are observable only around the age of 10 years, whereas adult-like semantic processes are established much earlier (Friederici, 1983).

The second issue discussed on the basis of the present results and those reported in the literature is the time course of syntactic and semantic processes. The model presented in Fig. 4 is an extension of an earlier model (Friederici, 2002) based on novel findings, in particular those of the patient studies reported here. The model assumes three functionally and temporally separable stages of processing: during phase 1 processes of local structure building take place, during phase 2 lexical-semantic and thematic processes are engaged and in phase 3 processes of syntactic revision and final integration.

After the acoustic/phonetic analysis supported by the auditory cortex (color coded in blue) initial syntactic processes of local structure building (phase 1), reflected in the ELAN in the ERP, take place. These processes are supported by the anterior portion of the STG and the frontal operculum as indicated by fMRI and MEG studies (color coded in red).

Although not discussed in detail in this article a brief description of processes taking place during phase 2 will be presented. Lexical-semantic and thematic processes are supported by a temporofrontal network involving the middle and possibly the posterior portion of the STG and MTG and BA 45/47 in the IFG as indicated by a number of PET and fMRI studies not discussed here (color coded in orange). Lexical-semantic processes are reflected in the N400 component in the ERP (e.g., Kutas and Hillyard, 1984). Processes of thematic role assignment which are based on morphosyntactic information signaling agreement between different phrases or between elements within a phrase are reflected by a left anterior negativity between 300 and 500 ms (LAN), a component which was not investigated in the present set of experiments but in a number of experiments in different languages including English (Coulson et al., 1998), Dutch (Gunter et al., 1997), German (Münte et al., 1997), Italian (Angrilli et al., 2002), and Hebrew (Deutsch and Bentin, 2001). Most recently it has been argued on the basis of ERP findings in Italian that the two processing streams indicated as taking place during phase 2 should be modulated with an inherent seriality of morphosyntactic and semantic processes (De Vincenzi et al., 2003). Thematic role assignment in noncanonical sentences requires the identification of long-distance relations between a moved element and its original position in a sentence and/or the manipulation of moved elements during online sentence processing. These processes involving syntactic working memory are not reflected in a local ERP component but in a sustained left frontal negativity (Fiebach and Friederici, 2003; Fiebach et al., 2001). These latter syntactic processes are supported by BA 44/45 in the IFG (Ben-Shahar et al., 2003; Caplan et al., 1998, 2002; Fiebach et al., 2001; Newman et al., 2003; Stromswold et al., 1996) (indicated by white circle in Fig. 1).

Late syntactic processes, i.e., processes of syntactic revision, and late integration (phase 3) are reflected in the ERP component P600. The brain basis of these processes cannot yet be fully characterized. The available data suggest a neural network involving the left BG and possibly the left posterior STG (indicated by red-striped ellipses in Fig. 1).

The different studies discussed here give some support for the neural basis of those processes assumed to take place during phases 1 and 3. Moreover, they indicate that processes of local syntactic structure building of phase 1 functionally precede lexical-semantic processes assumed to be part of phase 2. The combined results presented here may add to our still insufficient knowledge of syntactic processes in the service of language comprehension.

\section{References}

Amunts, K., Schleicher, A., Schormann, T., Bürgel, U., Mohlberg, H., Uylings, H.B.M., Zilles, K., 1997. The cytoarchitecture of Broca's regions and its variability. NeuroImage 5, S353.

Amunts, K., Schleicher, A., Ditterich, A., Zilles, K., 2003. Broca's region: cytoarchitectonic asymmetry and developmental changes. J. Comp. Neurol. 465, 72-89.

Angrilli, A., Penolazzi, B., Vespignani, F., De Vincenzi, M., Job, R., Ciccarelli, L., Palomba, D., Stegagno, L., 2002. Cortical brain responses to semantic incongruity and syntactic violation in Italian language: an event-related potential study. Neurosci. Lett. 322, 5-8.

Bates, E., MacWhinney, B., 1987. Competition, variation and language learning, in: MacWhinney, B. (Ed.), Mechanisms of language acquisition, Erlbaum, Hillsdale, NJ, pp. 157-194

Ben-Shahar, M., Hendler, T., Kahn, I., Ben-Bashat, D., Grodzinsky, Y., 2003. The neural reality of syntactic transformations: evidence from fMRI. Psychol. Sci. 14, 433-440.

Bornkessel, I., 2002. The argument dependency model: a neurocognitive approach to incremental interpretation. MPI Ser. Cognit. Neurosci. 28.

Caplan, D., 1995. The cognitive neuroscience of syntactic processing, in: Gazzaniga, M.S. (Ed.), The cognitive neurosciences, MIT Press, Cambridge, MA, pp. 871-879.

Caplan, D., 2001. Functional neuroimaging studies of syntactic processing. J. Psycholinguistic Res. 30, 297-320.

Caplan, D., Alpert, N., Waters, G., 1998. Effects of syntactic structure and propositional number on patterns of regional blood flow. J. Cognit. Neurosci. 10, 541-552.

Caplan, D., Vijayan, S., Kuperberg, G., West, C., Waters, G., Greve, D., Dale, A.M., 2002. Vascular responses to syntactic processing: eventrelated fMRI study of relative clauses. Hum. Brain Mapping 15, 26-38.

Coulson, S., King, J.W., Kutas, M., 1998. Expect the unexpected: eventrelated brain response to morphosyntactic violations. Lang. Cognit. Processes 13, 21-58. 
De Vincenzi, M., Job, R., Di Matteo, R., Angrilli, A., Penalozzi, B., Ciccarelli, L., Vespignani, F., 2003. Differences in the perception and time course of syntactic and semantic violations. Brain Lang. 85, 280-296.

Deutsch, A., Bentin, S., 2001. Syntactic and semantic factors in processing gender agreement in Hebrew: evidence from ERPs and eye movements. J. Memory Lang. 45, 200-224.

Embick, D., Marantz, A., Miyashita, Y., O’Neil, W., Sakai, K.L., 2000. A syntactic specialization for Broca's area. Proc. Natl. Acad. Sci. USA 97, 6150-6154.

Fiebach, C.J., Friederici, A.D., 2003. Syntactic complexity and verbal working memory load: efMRI demonstrates an interaction in Broca's area. J. Cognit. Neurosci. Suppl. 141

Fiebach, C.J., Schlesewsky, M., Friederici, A.D., 2001. Syntactic working memory and the establishment of filler-gap dependencies: insights from ERPs and fMRI. J. Psycholinguistic Res. 30, 321-338.

Fodor, J.A., 1983. The modularity of mind: an essay on faculty psychology. MIT Press, Cambridge, MA.

Frazier, L., Fodor, J.D., 1978. The sausage machine: a new two-stage model of the parser. Cognition 6, 291-325.

Friederici, A.D., 1983. Children's sensitivity to function words during sentence comprehension. Linguistics 21, 717-739.

Friederici, A.D., 1995. The time course of syntactic activation during language processing: a model based on neuropsychological and neurophysiological data. Brain Lang 50, 259-281.

Friederici, A.D., 2002. Towards a neural basis of auditory sentence processing. Trends Cognit. Sci. 6, 78-84.

Friederici, A.D., Gunter, T.C., Hahne, A., Mauth, K., 2003a. The relative timing of syntactic and semantic processes during sentence comprehension. NeuroReport (in press).

Friederici, A.D., Hahne, A., Mecklinger, A., 1996. The temporal structure of syntactic parsing: early and late ERP effects elicited by syntactic anomalies. J. Exp. Psychol. Learn. Memory Cognit. 22, 1-31.

Friederici, A.D., Hahne, A., von Cramon, D.Y., 1998. First-pass versus second-pass parsing processes in a Wernicke's and a Broca's aphasic: electro-physiological evidence for a double dissociation. Brain Lang. $62,311-341$

Friederici, A.D., Kotz, S.A., Werheid, K., Hein, G., von Cramon, D.Y., 2003b. Syntactic comprehension in Parkinson's disease: investigating early automatic and late integrational processes using event-related brain potentials. Neuropsychology 17, 133-142.

Friederici, A.D., Mecklinger, A., 1996. Syntactic parsing as revealed by brain responses: first-pass and second-pass parsing processes. J. Psycholinguistic Res. 25, 157-176.

Friederici, A.D., Opitz, B., von Cramon, D.Y., 2000a. Segregating semantic and syntactic processes during word processing in the human brain: an fMRI investigation of different word types. Cereb. Cortex 10 698-705.

Friederici, A.D., Pfeifer, E., Hahne, A., 1993. Event-related brain potentials during natural speech processing: effects of semantic, morphological and syntactic violations. Cognit. Brain Res. 1, 183-192.

Friederici, A.D., Rüschemeyer, S.-A., Hahne, A., Fiebach, C.J., 2003c. The role of left inferior frontal and superior temporal cortex in sentence comprehension: localizing syntactic and semantic processes. Cereb. Cortex 13, 170-177.

Friederici, A.D., von Cramon, D.Y., Kotz, S.A., 1999. Language related brain potentials in patients with cortical and subcortical left hemisphere lesions. Brain 122, 1033-1047.

Friederici, A.D., Wang, Y., Herrmann, C.S., Maess, B., Oertel, U., 2000b. Localization of early syntactic processes in frontal and temporal cortical areas: a magnetoencephalographic study. Hum. Brain Mapping 11, 1-11.

Frisch, S., Kotz, S.A., von Cramon, D.Y., Friederici, A.D., 2003. Why the P600 is not just a P300: the role of the basal ganglia. Clin. Neurophysiol. 114, 336-340.
Frisch, S., Schlesewsky, M., 2001. The N400 reflects problems of thematic hierarchizing. NeuroReport 12, 3391-3394.

Gunter, T.C., Friederici, A.D., Schriefers, H., 2000. Syntactic gender and semantic expectancy: ERPs reveal early autonomy and late interaction. J. Cognit. Neurosci. 12, 556-568.

Gunter, T.C., Stowe, L.A., Mulder, G., 1997. When syntax meets semantics. Psychophysiology 34, 660-676.

Hagoort, P., Brown, C., Groothusen, J., 1993. The syntactic positive shift (SPS) as an ERP measure of syntactic processing. Lang. Cognit. Processes 8, 439-483.

Hahne, A., Friederici, A.D., 1999. Electrophysiological evidence for two steps in syntactic analysis: early automatic and late controlled processes. J. Cognit. Neurosci. 11, 194-205.

Hahne, A., Friederici, A.D., 2002. Differential task effects on semantic and syntactic processes as revealed by ERPs. Cognit. Brain Res. 13, 339356.

Hickok, G., Poeppel, D., 2000. Towards a functional neuroanatomy of speech perception. Trends Cognit. Sci. 4, 131-138.

Holcomb, P.J., Neville, H.J., 1991. Natural speech processing: an analysis using event-related brain potentials. Psychobiology 19, 286-300.

Kaan, E., Harris, A., Gibson, E., Holcomb, P., 2000. The P600 as an index of syntactic integration difficulty. Lang. Cognit. Processes 15, 159-201.

Kaan, E., Swaab, T.Y., 2002. The brain circuitry of syntactic comprehension. Trends Cognit. Sci. 6, 350-356.

Knoesche, T.R., Maess, B., Friederici, A.D., 1999. Processing of syntactic information monitored by brain surface current density mapping based on MEG. Brain Topogr. 12, 75-87.

Kotz, S.A., Friederici, A.D., 2003a. Electrophysiology of normal and pathological language processing. J. Neurolinguistics 16, 43-58.

Kotz, S.A., Frisch, S., von Cramon, D.Y., Friederici, A.D., 2003b. Syntactic language processing: ERP lesion data on the role of the basal ganglia. J. Int. Neuropsychol. Soc. 9, 1053-1060.

Kotz, S.A., von Cramon, D.Y., Friederici, A.D. 2003c. Differentiation of syntactic processes in the left and right anterior temporal lobe: ERP evidence from lesion patients. Brain Lang. 87, 135-136.

Kutas, M., Federmeier, K.D., 2000. Electrophysiology reveals semantic memory use in language comprehension. Trends Cognit. Sci. 4, 463-470.

Kutas, M., Hillyard, S.A., 1984. Brain potentials during reading reflect word expectancy and semantic association. Nature 307, 161-163.

Kutas, M., van Petten, C., 1994. Psycholinguistics electrified: event-related brain potential investigations. in: Gernsbacher, M.A. (Ed.), Handbook of psycholinguistics. Academic Press, San Diego, pp. 83-143.

MacDonald, M.C., Pearlmutter, N.J., Seidenberg, M.S., 1994. The lexical nature of syntactic ambiguity resolution. Psychol. Rev 101, 676-703.

Marslen-Wislon, W., Tyler, L.K., 1980. The temporal structure of spoken language understanding. Cognition 8, 1-71.

Mecklinger, A., Schriefers, H., Steinhauer, K., Friederici, A.D., 1995. The processing of relative clauses varying on syntactic and semantic dimensions: an analysis with event-related potentials. Memory Cognit. 23, 477-494

Meyer, M., Friederici, A.D., von Cramon, D.Y., 2000. Neurocognition of auditory sentence comprehension: event-related fMRI reveals sensitivity to syntactic violations and task demands. Cognit. Brain Res. 9, 19-33.

Münte, T.F., Heinze, H., Mangun, G.R., 1993. Dissociation of brain activity related to syntactic and semantic aspects of language. J. Cognit. Neurosci. 5, 335-344.

Münte, T.F., Matzke, M., Johannes, S., 1997. Brain activity associated with syntactic incongruencies in words and pseudo-words. J. Cognit. Neurosci. 9, 318-329.

Neville, H.J., Nicol, J., Barss, A., Forster, K.I., Garrett, M.F., 1991. Syntactically based sentence processing classes: evidence from eventrelated brain potentials. J. Cognit. Neurosci. 3, 151-165. 
Newman, S.D., Just, M.A., Keller, T.A., Roth, J., Carpenter, P.A., 2003. Differential effects of syntactic and semantic processing on the subregions of Broca's area. Cognit. Brain Res. 16, 297-307.

Osterhout, L., Holcomb, P.J., 1992. Event-related brain potentials elicited by syntactic anomaly. J. Memory Lang. 31, 785-806.

Osterhout, L., Holcomb, P.J., 1993. Event-related potentials and syntactic anomaly: evidence of anomaly detection during the perception of continuous speech. Lang. Cognit. Processes 8, 413-438.

Osterhout, L., Holcomb, P.J., Swinney, D.A., 1994. Brain potentials elicited by garden path sentences: evidence of the application of verb information during parsing. J. Exp. Psychol. Learn. Memory Cognit. 20, 786-803.

Penke, M., Weyerts, H., Gross, M., Zander, E., Münte, T.F., Clahsen, H., 1997. How the brain processes complex words: an ERP-study of German verb inflections. Cognit. Brain Res. 6, 37-52.
Rösler, F., Friederici, A.D., Pütz, P., Hahne, A., 1993. Event-related brain potentials while encountering semantic and syntactic constraint violations. J. Cognit. Neurosci. 5, 345-362.

Stromswold, K., Caplan, D., Alpert, N., Rauch, S., 1996. Localization of syntactic comprehension by positron emission tomography. Brain Lang. 52, 452-473.

Talairach, J., Tournoux, P., 1988. Co-planar stereotaxic atlas of the human brain. 3-Dimensional proportional system: an approach to cerebral imaging. Thieme, Stuttgart.

Taraban, R., McClelland, J.R., 1988. Constituent attachment and thematic role assignment in sentence processing: influence of context-based expectations. J. Memory Lang. 27, 597-632.

Van Petten, C., 1993. A comparison of lexical and sentence-level context effects in event-related potentials. Lang. Cognit. Processes $8,485-531$. 